\title{
Otologic Active Middle Ear Implants
}

\author{
Jeon Mi Lee and Jae Young Choi \\ Department of Otorhinolaryngology, Yonsei University College of Medicine, Seoul, Korea
}

\section{인공 중이 이식술의 최신 지견}

\author{
이 전 미·최 재 영 \\ 연세대학교 의과대학 이비인후과학교실
}

\author{
Received July 18, 2016 \\ Revised July 23, 2016 \\ Accepted July 23, 2016 \\ Address for correspondence \\ Jae Young Choi, MD, PhD \\ Department of Otorhinolaryngology, \\ Yonsei University \\ College of Medicine, \\ 50 Yonsei-ro, Seodaemun-gu, \\ Seoul 03722, Korea \\ Tel $+82-2-2228-3626$ \\ Fax $+82-2-393-0580$ \\ E-mail jychoi@yuhs.ac
}

\begin{abstract}
Implantable devices for aural rehabilitation are widely developed worldwide. In the manuscript, we review the implantable middle ear hearing devices currently in use, such as the Vibrant Soundbridge system (Med-El Corporation), the MAXUM system (Ototronix LLC), the fourthgeneration of Carina prosthesis (Otologics LLC), and the Esteem device. Implantable hearing aids will unquestionably be the major drivers of advancement in otologic practice in early future, improving the quality of life of an increasingly aged population, which will consequently require increased levels of hearing support.
\end{abstract}

Korean J Otorhinolaryngol-Head Neck Surg 2016;59(12):807-12

Key Words Carina $\cdot$ Esteem · MAXUM $\cdot$ Middle ear implant · Vibrant Soundbridge.

\section{서 론}

중이 이식술은 중고도의 감각 신경성 난청 환자를 위해 발 명된 기술로, 특히 고전적 보청기와 인공 와우 이식술의 적 응증 모두에 해당하지 않는 환자에게 유용한 기술이다. 경도 에서 중등도 난청의 경우 고전적 보청기를 통해 어느 정도 충 분한 청력 재활이 가능하지만, 중고도 이상의 난청 환자에게 서는 폐쇄 효과나 외이도의 불편감, 소리의 왜곡, 되울림 현 상, 소음 속 청취의 어려움 및 고주파의 증폭 제한 등의 이유 로 보청기를 구입한 10명 중 4명 만이 보청기를 사용하고 있 는 실정이다. ${ }^{1)}$ 더욱이 감각 신경성 난청 환자는 신경기능이 저하되어 있기 때문에 보청기를 사용하여 소리를 증폭할 경 우 그 불쾌감이 더 크다. ${ }^{2)}$ 수술의 과거력이나 염증 등의 이유 로 보청기를 착용하기 힘든 경우도 있다.

이처럼 보청기로 충분한 청각 이득을 얻지 못하지만, 고전 적 인공 와우 이식술의 적응증이 되지 않는 환자들을 위한 대안으로 고안된 것이 전기-소리 자극 하이브리드 인공 와우 (electroacousic stimulation, EAS; Hybrid CI)이다. EAS는 기 존보다 짧은 전극을 삽입함으로써 기저부의 고주파를 전기
자극하면서 동시에 첨단부의 저주파를 보존하는 방법으로, 청취 이해도나 방향성, 그리고 음악 청취 등에서 고전적 인공 와우 이식술보다 더 훌륭한 효과를 내는 것으로 보고되었 다. ${ }^{3)}$ 그러나 전극을 삽입하는 과정 중 와우가 손상되거나 난 청의 진행으로 인하여 저주파 청력을 보존하지 못할 가능성 이 늘 존재하며, 그런 경우 첨단부에 충분한 자극을 주기 위 해 삽입하였던 전극을 일반 전극으로 교체해야 하는 경우가 생기기도 한다.

중이 이식술은 보청기와 인공 와우 이식술, 이 두 가지 청력 재활의 경계에 존재하는 중고도 난청 환자들에게 도움을 줄 수 있다. 본문에서는 현재 국내 및 해외에서 사용 중인 중이 이 식구를 소개하고자 한다.

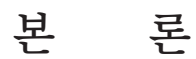

1953년, Wilska 등 ${ }^{4}$ 이 전자기장을 이용해 고막에 부착시 킨 철조각을 자극하여 진동을 형성시켜 소리 전달에 성공한 것을 시작으로 중이 이식에 대한 다양한 시도가 이루어졌다. 수년간의 다양한 시도 끝에 두 가지 기술이 현재의 중이 이식 
술을 대표하게 되었는데, 이는 압전 방식(piezoelectric technique)과 전자기장 방식(electromagnetic technique)이다(Fig. 1). 압전 방식은 전류가 흐를 때 결정체(crystal)의 구조가 바뀌 는 성질을 이용하여 소리를 전달하며, 전자기장 방식은 자기 장을 형성시켜 이소골에 부착한 철물 구조를 움직이는 방법 으로 소리의 전달을 가능하게 한다. 압전 방식은 자기장을 형 성시킬 필요가 없기 때문에 전자기장 방식보다 배터리 수명이 더 길며, MRI 촬영이 가능하다. 하지만 현재까지의 기술력으
로는 수술이 어렵고 부작용이 많으며 기기의 안정성에 문제 가 있어 현재까지의 중이 이식술은 주로 전자기장 방식이 이 용되고 있다.

\section{전자기장 방식의 인공 중이 이식구}

\section{Vibrant Soundbridge}

Vibrant Soundbridge(VSB; Med-El Corporation, Inns-
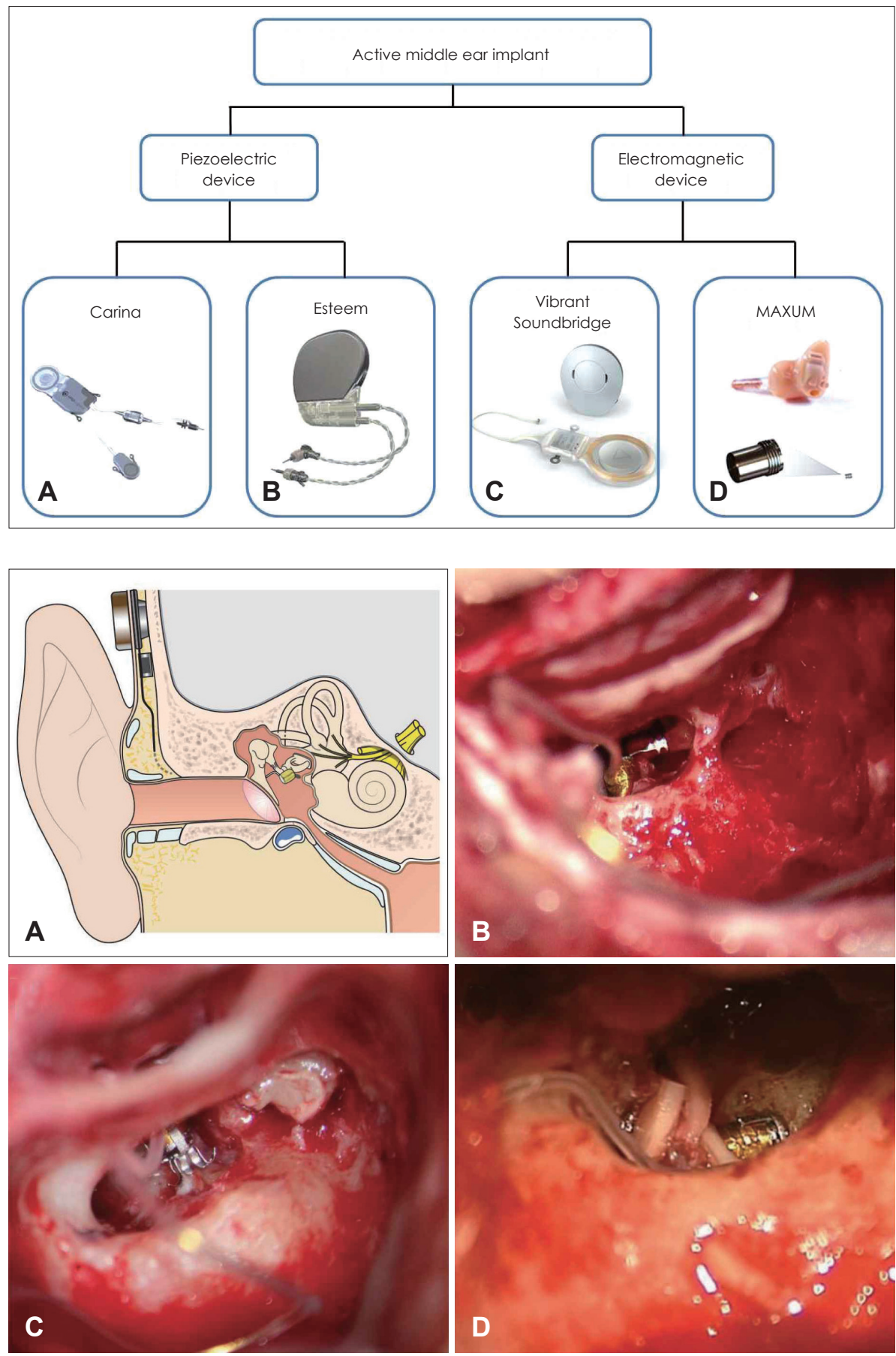

Fig. 1. Classification of active middle ear implant. Photo provided courtesy of Otologics LLC (A), Envoy Medical Corporation (B), Med-El Corporation (C), and Ototronix LLC (D).
Fig. 2. Vibrant Soundbridge system. (A) The microphones attached to the external audio processor pick up sound and convert it to electrical signals, then transmit the signals to the internal portion of the system by magnetic induction. The receiver (VORP) receives the waveform output of the microprocessor and sends a corresponding electrical current to the floating mass transducer, which vibrates under magnetic field. FMT can be applied to incus (B), stapes (C) or round window (D). Photo (A) provided courtesy of Med-El Corporation. VORP: vibrating ossicular prosthesis, FMT: floating mass transducer. 
bruck, Austria)는 존재하는 인공 중이 이식구 중 최초로 미국 $\mathrm{FDA}$ 승인을 받은 이식구로, 작년 10월 국내에서도 보험 급여 가 인정되어 활발히 사용되고 있다. VSB는 소리 정보를 수신, 변환하여 내부 장치로 전달하는 외부 장치(Amade ${ }^{\circledR}$ )와 내부 수신기(vibrating ossicular prosthesis, VORP)로 이루어진 부분 이식형 이식구이다. 외부 장치는 지름 $2.5 \mathrm{~cm}$, 두께 $1 \mathrm{~cm}$ 가량으로, 두 개의 마이크를 이용하여 소리를 수신한다. 수 신된 소리 정보는 전기 정보로 변환되어 자기 유도를 통해 내부 수신기로 전달되는 데 이 과정에서 에너지가 소모되며, 소모된 에너지는 외부 장치의 건전지를 교체함으로써 공급 할 수 있다. VORP는 변환된 전기 자극을 수신하여 floating mass transducer(FMT)로 전달한다. FMT는 미세한 자석 구 조를 포함하고 있어, 전기 정보가 전달되면서 발생하는 자기 장의 영향을 받아 진동하여 내이로 소리를 전달하게 된다 (Fig. 2A).

초기의 VSB는 FMT를 침골의 장돌기에 연결하도록 고안되 어 주로 감각 신경성 난청 환자에게 사용하였으나 점차 중이 구조물의 상태에 따라 정원창, 등골, 혹은 난원창 등에 적용 하여 우수한 결과를 보이면서, 2008년 VSB의 적응증은 전 음성 또는 혼합성 난청 환자에게로 확대되었다(Fig. $2 \mathrm{~B}, \mathrm{C}$, and D). 개인차가 있을 수 있지만 감각 신경성 난청 환자에서 침골의 장돌기 혹은 단돌기를 자극할 경우 약 $25 \sim 30 \mathrm{~dB}$ 의 이득이 기대되며,") 혼합성 난청 환자에서 등골 및 정원창을 자극했을 때 각각 30 35 dB, 30 55 dB까지 이득이 보고되 었다. ${ }^{6}$

$\mathrm{VSB}$ 는 외이도를 막지 않는다는 점에서 폐쇄 효과나 되울 림 현상에서 자유로울 뿐 아니라, 정상 생리 구조를 따르기 때문에 청각 기능을 회복한다는 장점이 있다. 현재 FDA에서 는 $1.5 \mathrm{~T}$ 까지의 자기공명영상촬영이 승인되었으며, 술식은 가역적이기 때문에 청각의 손상 없이 제거가 가능하다. 또한 이식 후에는 간단히 외부 장치를 교체함으로써 최신 기술을 업데이트 하여 사용할 수 있다는 것도 장점이다. 그렇지만 공 통적으로 중이의 어느 구조를 자극하여도 $500 \mathrm{~Hz}$ 이하의 저 주파 증폭이 어렵다는 단점이 있다. 이는 아마도 FMT의 무 게 효과 때문으로 생각된다.

\section{MAXUM}

MAXUM(Ototronix LLC, Houston, TX, USA)은 2009 년에 출시된 부분 이식형 이식구이다. 이는 2001년 FDA 승인 을 받은 SOUNDTEC Direct Drive Hearing System(SOUNDTEC Inc., Oklahoma City, OK, USA)에 기반을 둔 방 식으로, SOUNDTEC에 사용한 귀걸이형 외부 장치 대신 귓 속형 외부 장치를 사용하였다. 외부 장치는 마이크를 통하여
수신한 소리 정보를 전기 신호로 변환시켜 내부 장치로 전달 하는 과정에서 자기장을 형성한다. 침골-등골 연결부(incudostapedial joint, IS joint)에 이식한 자석은, 이 자기장 신호 에 동기화되어 진동을 발생시켜 소리 신호를 내이로 전달한 다. 이때 외부 장치가 형성하는 자기장 영역 내에 내부 자석 장치가 위치해야 하기 때문에 외부 장치는 맞춤 제작되어야 한다(Fig. 3).

MAXUM은 귓속형 외부 장치를 사용함으로써 외이의 음 집 효과(baffle effect)를 최대화할 수 있다. 뿐만 아니라 부분 마취하 경외이도 접근법(transcanal approach)으로 IS joint를 노출시켜 간단히 clip형 내부 장치를 이식할 수 있기 때문에 수술 및 재원 기간이 짧다는 장점이 있다. 또한 자기공명영상 촬영이 $\mathrm{FDA}$ 승인하에 0.3 T까지 안전하게 사용 가능하다. 그 러나 현재까지 MAXUM은 감각 신경성 난청 환자에게만 사 용할 수 있다.

MAXUM은 수술 전과 비교해 보았을 때 $25 \mathrm{~dB}$ 정도의 청 력 이득을 보이며,") 이는 수술 전 보청기를 사용할 때보다 약
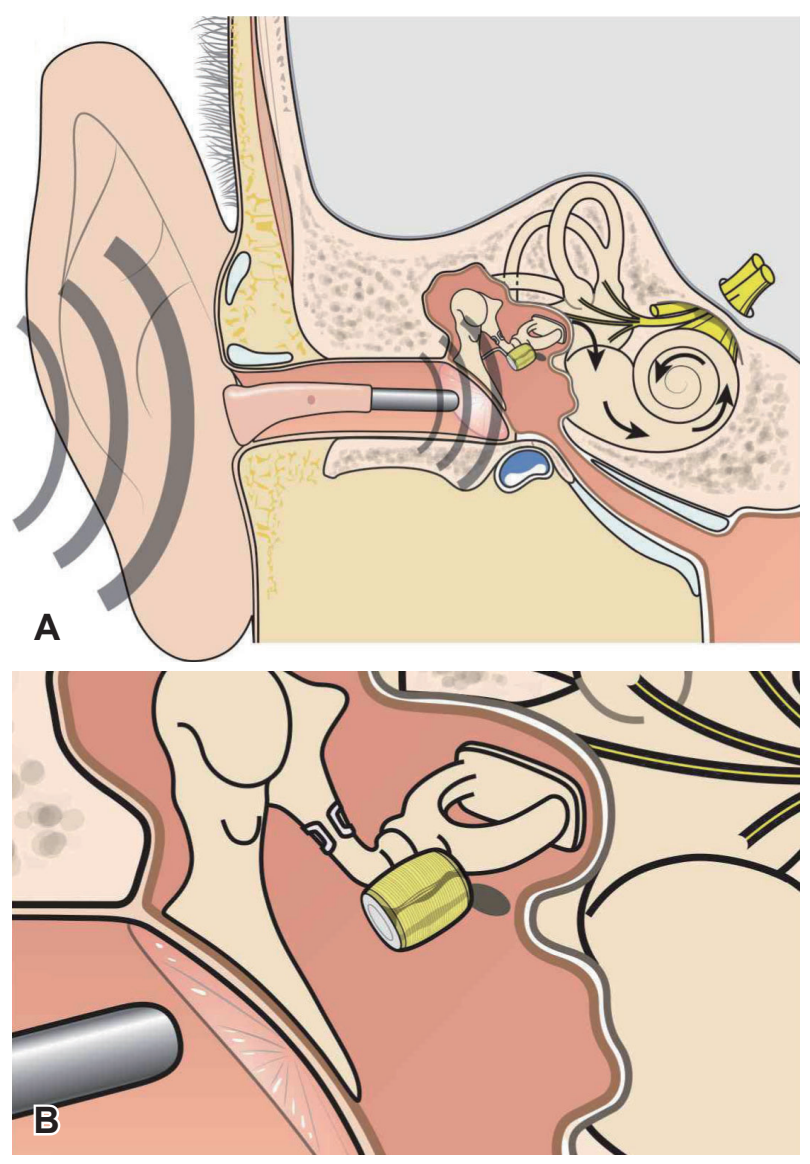

Fig. 3. MAXUM system. Semi-implantable MAXUM hearing implant utilizes an open-fit completely-in-the-canal, electromagnetic sound processor (A). To generate the optimal magnetic field, sound processor should be custom made to be placed no farther than $2 \mathrm{~mm}$ from the implanted magnet $(B)$. 
$10 \mathrm{~dB}$ 정도 우수한 결과이다. ${ }^{8,9)} \mathrm{MAXUM}$ 은 특히 중-고주파 이득이 우수하여 $2,3,4 \mathrm{kHz}$ 평균을 비교했을 때 $50 \mathrm{~dB}$ 이상 의 이득을 보여 ${ }^{10)}$ 경사형 난청 환자(sloping type)에게 큰 도 움을 줄 수 있을 것으로 생각된다.

\section{압전 방식의 인공 중이 이식구}

\section{Carina}

Carina(Otologics LLC, Boulder, CO, USA)는 현재 European Community의 승인하에 사용되고 있으며, FDA 승인을 위한 2상 임상 시험 중에 있는 완전 이식형 이식구이다. Carina 는 외부 소리를 수신하는 마이크와, 소리 정보를 변환하여 전 달하는 본체(배터리 포함), 그리고 실제 진동을 일으키는 작동 기(transducer)가 일체형으로 구성되어 있다(Fig. 4). 마이크는 측두근(temporalis muscle) 하 외이도 전방 혹은 후방, 또는 유양돌기 첨부(mastoid tip) 등 원하는 위치에 이식할 수 있으 며 위치에 따른 청력 이득에 차이는 없는 것으로 알려져 있 다. ${ }^{11)}$ 마이크는 골 피질에 스크류를 이용하여 고정할 수도 있 고, 연조직에 묻는 방식으로 고정할 수 있다.

감각 신경성 난청의 경우 단순 유양동 절제술 및 상고실 개 방술을 시행하여 노출된 추골이나 침골에 transducer를 접촉 시켜 소리를 전달하며, 등골이나 정원창, 난원창에도 같은 방 식을 이용하여 전도성 혹은 혼합성 난청에도 적용할 수 있다. 초기 transducer는 원통형으로 제작되었으나 정원창과 난원 창 등에 적용 시 손상을 최소로 하기 위해 볼 타입 등의 transducer도 제작되었다. 이 transducer는 실제 중이 구조물에 접촉하도록 고안되어 있기 때문에 목표물로부터 $5 \mathrm{~mm}$ 이상 떨어지지 않도록 주의하여야 한다. Carina는 평균 $25 \mathrm{~dB}$ 의 이득을 보이는 것으로 보고되고 있으며, ${ }^{12)}$ 그 이득은 감각 신 경성 난청보다 전도성 혹은 혼합성 난청에서 좀 더 우수한 것 으로 보고되고 있다. ${ }^{13)}$

압전 방식은 전자기장 방식보다 에너지 소모가 적다. 제조
사에서는 10 년 이상 배터리 교체 없이 이식구를 사용할 수 있 다고 발표했으며, 국소 마취하에서 transducer를 건드리지 않 고 배터리 부분만 교체할 수 있도록 제작되었다. 환자는 두 피를 사이에 두고 충전기를 이식된 배터리에 부착하여 충전 할 수 있으며, 1 시간 충전 시 32시간 사용할 수 있다고 알려져 있다. ${ }^{14)}$ 이러한 완전 이식형 이식구는 환자가 원하지 않아도 매일 이식구를 사용하게 됨으로써 새로운 소리의 전달 방식에 빨리 적응할 수 있다는 장점이 있으며, 외부 장치로부터 완전 히 자유로울 수 있기 때문에 일상 생활의 제약이 거의 없다.

그러나 Carina는 수신기 일체형 방식을 이용하여 되울림 현 상이 다수 보고되고 있다. 어음 처리기의 프로그램 조작을 통 해 되울림 현상을 일부 제거할 수 있지만, 수신기 위치를 재 조정해야 하거나 되울림 현상이 심하여 이득을 충분히 얻지 못한 채로 사용하는 경우도 보고되었다. ${ }^{15)}$ 또한 수신기를 이 식하기 위해 만든 공간이 완전히 치유되어 수신기가 고정되 기 전까지는 고개를 돌리거나 움직일 때 발생하는 소리가 수 신기를 통해 감지될 수 있다. 제조사에서는 수신기를 두개골 에 이식했을 때에는 6개월, 경부의 연조직에 이식했을 때에 는 8 10개월 정도의 적응 기간이 필요하다고 발표하였다. ${ }^{13)}$

또한 현재 $20 \%$ 까지 기계 고장(device failure)이 보고되었 다. 그러나 이는 개선될 수 있는 부분이라고 생각되며, 그럼에 도 불구하고 환자의 높은 만족도 ${ }^{16)}$ 와 반대측 귀에도 이식을 원한다는 설문 결과 ${ }^{16)}$ 는 Carina의 유용성을 잘 보여준다.

\section{Esteem}

Esteem(Envoy Medical Corporation, White Bear Lake, $\mathrm{MN}, \mathrm{USA}$ )은 최초로 $\mathrm{FDA}$ 승인을 받은 완전 이식형 이식구 로 감각 신경성 난청 환자에게 적용할 수 있다. Esteem은 두 개의 transducer를 가지고 있는데 하나는 sensor transducer 로 침골에 부착되어 진동을 감지하는 역할을 한다. 감지된 진 동 정보는 어음 처리기를 통해 전기 정보로 변환되어 등골의 머 리에 부착된 driver transducer로 전달되고 최종적으로 등골

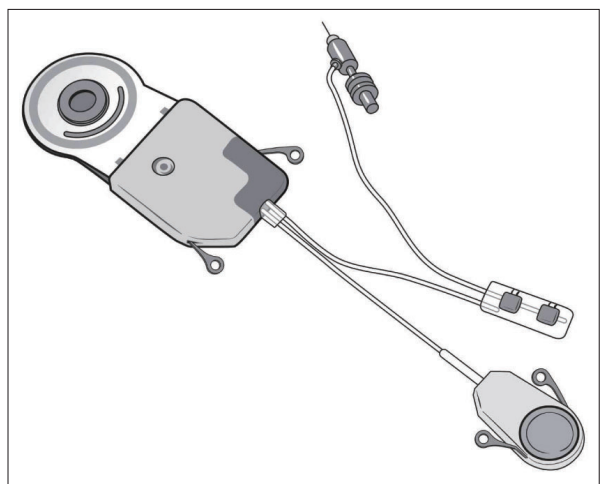

A

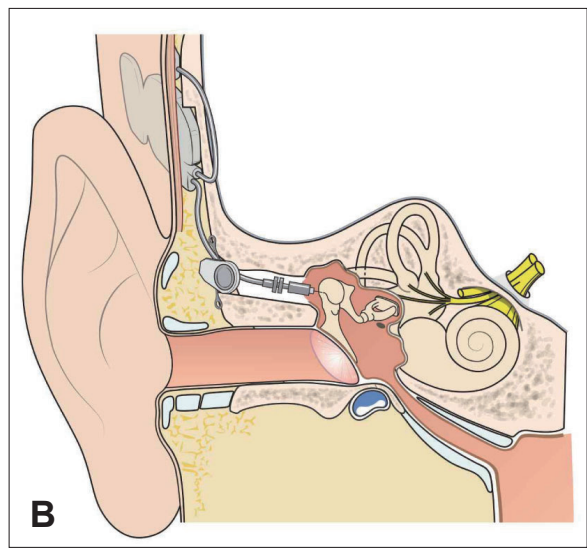

Fig. 4. Carina system (A). Sounds are captured by the microphone and relayed to the sound processor within the implant capsule. The sound processor analyses the sound information, amplifies it according to the programmed settings, and converts it into electrical signals that are relayed to the transducer attached to the incus. This transducer translates electrical signals into a mechanic motion that directly stimulates the ossicular chain or the round window. Ossicles are not disarticulated (B). 


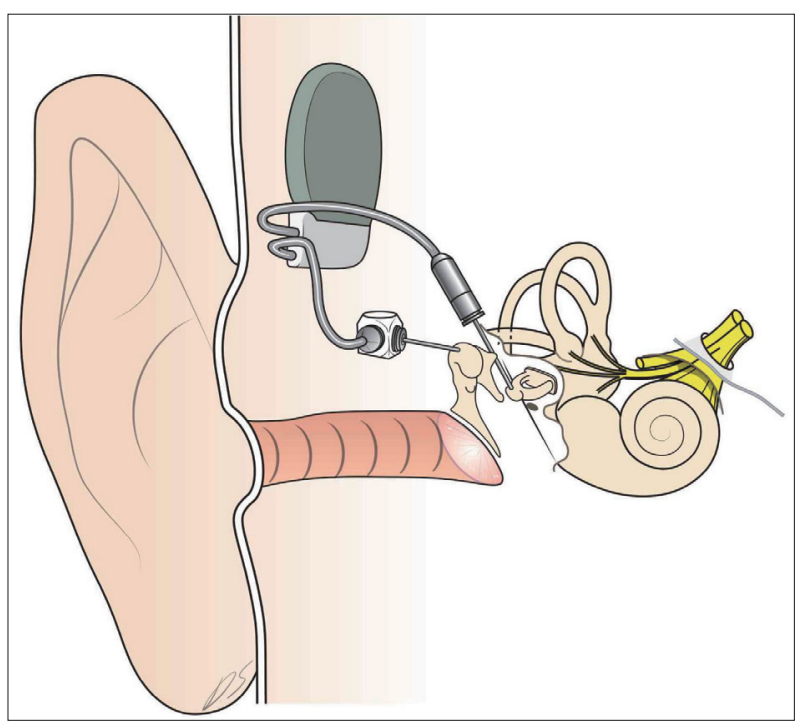

Fig. 5. Esteem II system. Sound vibrates the tympanic membrane and the sensor microphone senses vibrations from the incus. The sound processor receives electrical signals from the sensor, modifies the signals to specified settings, and sends the signals to the driver. The driver transforms the modified signals into mechanical vibrations. Vibrations are delivered directly to the stapes.

의 진동을 형성하여 내이로 소리 정보를 전달한다(Fig. 5). 이 때 transducer와 각 이소골은 glass ionomer cement를 이용 하여 부착, 고정한다. 외부에서 정보를 받아들이는 경로와 내이로 정보를 전달하는 경로의 중첩을 차단하기 위하여 유 양동 절제술 및 후고실 개방술을 시행하여 IS joint를 분리 하는 과정이 필수적이며, 이 때 후고실 개방술은 최대한 넓 게 이루어져야 한다. ${ }^{17)}$ 이 과정 중 5\%에서 안면 신경 손상 ${ }^{177}$ 과 $60 \%$ 의 고삭 신경 손상이 보고되었다. ${ }^{18)}$ 또한 이식구가 차지 하는 공간이 커서 유양동이 작거나 경화된 경우 사용이 제한 될 수 있다.

그러나 경로의 중첩을 차단함으로써 Carina에서 문제가 되 었던 되울림 현상에서 자유로울 수 있고, 비교적 많은 이득 을 제공할 수 있다. ${ }^{17)}$ 또한 완전 이식형 배터리의 교체 기간이 7 10년 이상으로 길며 국소 마취하에 간단한 교체가 가능하 게 제작되어 일상 생활의 제약이 거의 없다는 장점이 있다.

\section{결 론}

현재의 인공 중이 이식구는 초기 발전 단계에 있지만, 멀 지 않은 미래에 곧 현재의 한계점을 보완하여 청력 재활의 큰 줄기가 될 것으로 생각된다. 인공 중이 이식술은 고식적 보청기나 인공 와우 이식술의 적응증에 해당되지 않는 중고 도 난청 환자부터 중이 수술 기왕력이나 기형으로 인해 정상 소리 전달 과정이 손상된 환자에게 폭넓게 사용될 수 있어 많 은 환자들에게서 삶의 질을 증진시킬 수 있을 것이다.

\section{Acknowledgments}

The authors would like to thank Dong-Su Jang, MFA (Medical Illustrator, Medical Research Support Section, Yonsei University College of Medicine, Seoul, Korea) for his help with the illustrations.

\section{REFERENCES}

1) Kochkin S. MarkeTrak VIII: the key influencing factors in hearing aid purchase intent. Hear Revi 2012;19(3):12-25.

2) Mueller HG, Ricketts TA, Bentler R. Modern hearing aids: prefitting testing and selection considerations. 1st ed. San Diego, CA: Plural Publishing Inc.;2013.

3) Gifford RH, Dorman MF, Skarzynski H, Lorens A, Polak M, Driscoll CL, et al. Cochlear implantation with hearing preservation yields significant benefit for speech recognition in complex listening environments. Ear Hear 2013;34(4):413-25.

4) Goode RL, Rosenbaum ML, Maniglia AJ. The history and development of the implantable hearing aid. Otolaryngol Clin North Am 1995; 28(1):1-16.

5) Kahue CN, Carlson ML, Daugherty JA, Haynes DS, Glasscock ME 3rd. Middle ear implants for rehabilitation of sensorineural hearing loss: a systematic review of FDA approved devices. Otol Neurotol 2014;35(7):1228-37.

6) Luers JC, Hüttenbrink KB, Zahnert T, Bornitz M, Beutner D. Vibroplasty for mixed and conductive hearing loss. Otol Neurotol 2013;34(6):1005-12.

7) Silverstein H, Atkins J, Thompson JH Jr, Gilman N. Experience with the SOUNDTEC implantable hearing aid. Otol Neurotol 2005;26(2): 211-7.

8) Roland PS, Shoup AG, Shea MC, Richey HS, Jones DB. Verification of improved patient outcomes with a partially implantable hearing aid, The SOUNDTEC direct hearing system. Laryngoscope 2001; 111(10):1682-6.

9) Hough JV, Matthews P, Wood MW, Dyer RK Jr. Middle ear electromagnetic semi-implantable hearing device: results of the phase II SOUNDTEC direct system clinical trial. Otol Neurotol 2002;23(6): 895-903.

10) Hunter JB, Carlson ML, Glasscock ME 3rd. The ototronix MAXUM middle ear implant for severe high-frequency sensorineural hearing loss: preliminary results. Laryngoscope 2016;126(9):2124-7.

11) Martin C, Deveze A, Richard C, Lefebvre PP, Decat M, Ibañez LG, et al. European results with totally implantable carina placed on the round window: 2-year follow-up. Otol Neurotol 2009;30(8):1196-203.

12) Pulcherio JO, Bittencourt AG, Burke PR, Monsanto RC, de Brito R, Tsuji RK, et al. Carina ${ }^{\circledR}$ and Esteem ${ }^{\circledR}$ : a systematic review of fully implantable hearing devices. PLoS One 2014;9(10):e110636.

13) Bruschini L, Berrettini S, Forli F, Murri A, Cuda D. The Carina $\odot$ middle ear implant: surgical and functional outcomes. Eur Arch Otorhinolaryngol 2016;273(11):3631-40.

14) Bittencourt AG, Burke PR, Jardim Ide S, Brito Rd, Tsuji RK, Fonseca $\mathrm{AC}$, et al. Implantable and semi-implantable hearing AIDS: a review of history, indications, and surgery. Int Arch Otorhinolaryngol 2014; 18(3):303-10.

15) Lachowska M, Niemczyk K, Yazbeck A, Morawski K, Bruzgielewicz A. First bilateral simultaneous implantation with fully implantable middle ear hearing device. Arch Med Sci 2012;8(4):736-42.

16) Kam AC, Sung JK, Yu JK, Tong MC. Clinical evaluation of a fully implantable hearing device in six patients with mixed and sensorineural hearing loss: our experience. Clin Otolaryngol 2012;37(3):240-4.

17) Kraus EM, Shohet JA, Catalano PJ. Envoy esteem totally implantable hearing system: phase 2 trial, 1-year hearing results. Otolaryngol Head Neck Surg 2011;145(1):100-9.

18) Gerard JM, Thill MP, Chantrain G, Gersdorff M, Deggouj N. Esteem 2 middle ear implant: our experience. Audiol Neurootol 2012;17(4): $267-74$. 


\section{정답 및 해설}

답 (5)

해 설 Choanal atresia의 case

가. 대개 일측성이다.

나. 골성>혼합성 폐쇄이며, 순수한 막성 폐쇄는 없다(한글판에서는 골성막성+혼합성).

(3) 일측성이 흔하므로, 출생 시 청색증과 호흡곤란의 증상보다는 추후에 콧물과 코막힘을 호소하는 경우가 흔하다.

(4) 양측성 질환인 경우, 근본적인 수술 치료 전에 구인강튜브나 McGover's nipple과 같은 구강기도를 확보한다.

참고문헌: Cummings CW. Cummings Otolaryngology-Head and Neck Surgery. 6th ed. Philadelphia: Elsevier Mosby;2010. p.2694-5. 